\title{
Tetralogy of Fallot without the infundibular septum-restricted growth of the pulmonary valve annulus after annulus preservation may render the right ventricular outflow tract obstructive
}

\author{
Ju-Yong Lim, MD, ${ }^{a}$ Wan-Sook Jang, MS, ${ }^{\mathrm{b}}$ Young-Hwue Kim, MD, ${ }^{\mathrm{b}}$ In-Sook Park, MD, ${ }^{\mathrm{b}}$ Jae-Kon Ko, MD, ${ }^{\mathrm{b}}$ \\ Moo-Song Lee, $\mathrm{MD}, \mathrm{PhD},{ }^{\mathrm{c}}$ and Tae-Jin Yun, $\mathrm{MD}, \mathrm{PhD}^{\mathrm{a}}$
}

\begin{abstract}
Objective: Tetralogy of Fallot (ToF) with infundibular septal deficiency (ISD) is commonly associated with postoperative right ventricular outflow tract obstruction (RVOTO), presumably caused by subpulmonary extension of ventricular septal defect (VSD) and restricted growth of the pulmonary valve annulus (PVA). We sought to determine the postoperative growth of the PVA after annulus preservation according to the presence or absence of the infundibular septum.
\end{abstract}

Methods: A retrospective review of 90 patients who underwent surgical repair of ToF between June 1997 and August 2008 was performed. Median age at operation was 9.5 months. Infundibular septum was absent in 15 (15/ $90,17 \%)$. PVA was preserved in 71 patients $(71 / 90,79 \%)$, including 13 patients with ISD $(13 / 15,87 \%)$.

\begin{abstract}
Results: Median follow-up duration was 39 months ( 2 months to 13 years). There was no early mortality and one late noncardiac death. Among the patients with PVA preservation, reoperation for RVOTO was performed in 4 patients $(4 / 71,6 \%)$, including 3 patients without the infundibular septum. ISD was identified as the only risk factor in reoperation for RVOTO after PVA preservation (RR: 21.85, $P=.007$ ). Among the patients who underwent repair with PVA preservation during infancy $(n=43)$, PVA (Z-score) increased postoperatively in patients with the infundibular septum $(+0.021 /$ month, $P=.009)$, whereas the changes in PVA (Z-score) were nonsignificant in patients with ISD $(-0.021$ /month, $P=.306)$, with a marginal intergroup difference $(P=.056)$.
\end{abstract}

Conclusions: PVA preservation in ToF with ISD may be associated with a higher risk for postoperative RVOTO, which can be attributed to the restricted growth of the PVA. (J Thorac Cardiovasc Surg 2011;141:969-74)

Of a myriad of operative strategies developed for congenital heart defects since the $1950 \mathrm{~s},{ }^{1}$ surgical correction of tetralogy of Fallot (ToF) has been one of the most significant accomplishments in terms of well-established preoperative risk analysis, finely designed therapeutic algorithm, and excellent surgical outcome. With extremely low postoperative mortality and morbidity in the contemporary series, debates over the surgical repair of ToF have moved on to how to improve long-term outcomes. Preservation of pulmonary valve annulus (PVA) upon initial repair has been considered to be crucial for the prevention of right ventricular dilatation and dysfunction, ${ }^{2-4}$ ventricular arrhythmia, ${ }^{5}$ and sudden death. ${ }^{6}$ However, the benefits of annulus preservation for marginally small PVAs are still controversial. Furthermore, certain

\footnotetext{
From the Division of Pediatric Cardiac Surgery ${ }^{\mathrm{a}}$ and the Division of Pediatric Cardiology, ${ }^{\mathrm{b}}$ Department of Preventive Medicine, ${ }^{\mathrm{c}}$ University of Ulsan, Asan Medical Center, Seoul, Republic of Korea.

Disclosures: Authors have nothing to disclose with regard to commercial support. Received for publication March 29, 2010; revisions received July 3, 2010; accepted for publication Aug 1, 2010; available ahead of print Sept 30, 2010.

Address for reprints: Tae-Jin Yun, MD, PhD, Division of Pediatric Cardiac Surgery, Asan Medical Center, 388-1 Poongnap-dong, Songpa-gu, Seoul, Republic of Korea, 138-736 (E-mail: tjyun@amc.seoul.kr).

$0022-5223 / \$ 36.00$

Copyright (c) 2011 by The American Association for Thoracic Surgery doi:10.1016/j.jtcvs.2010.08.023
}

anatomic features in ToF, such as infundibular septal deficiency (ISD), may preclude PVA preservation. In previous reports, ${ }^{7-9}$ it has been implied that repair of ToF with ISD, that is, subarterial (SA) or total conal defect (TCD)-type ventricular septal defect (VSD), is associated with a lower threshold for transannular patch (TAP) and a higher risk for postoperative right ventricular outflow tract obstruction (RVOTO). However, it is deemed implausible that ISD itself is a risk factor for TAP, given the fact that the feasibility of annulus preservation is determined mainly by the size of the PVA. Similarly, the hypothesis of a higher risk for RVOTO in this subset can not be tested properly if TAP is placed too frequently, which was one of the pitfalls of previous studies. $^{7-9}$ Since the late 1990s, we have employed an aggressive annulus preservation strategy for ToF in an effort to mitigate late complications of a dilatated and poorly functioning right ventricle. The probability of PVA preservation in our consecutive series has risen to $80 \%$, which strikingly coincides with that of others employing the same strategy. ${ }^{10-14}$ Thus, data from the patients enrolled in this study may well be suited for investigating the relationship between ISD and postoperative RVOTO. We speculate that ToF with ISD may present a higher risk for RVOTO once PVA is preserved upon repair, presumably because of subpulmonic extension of VSD, anchoring of the 


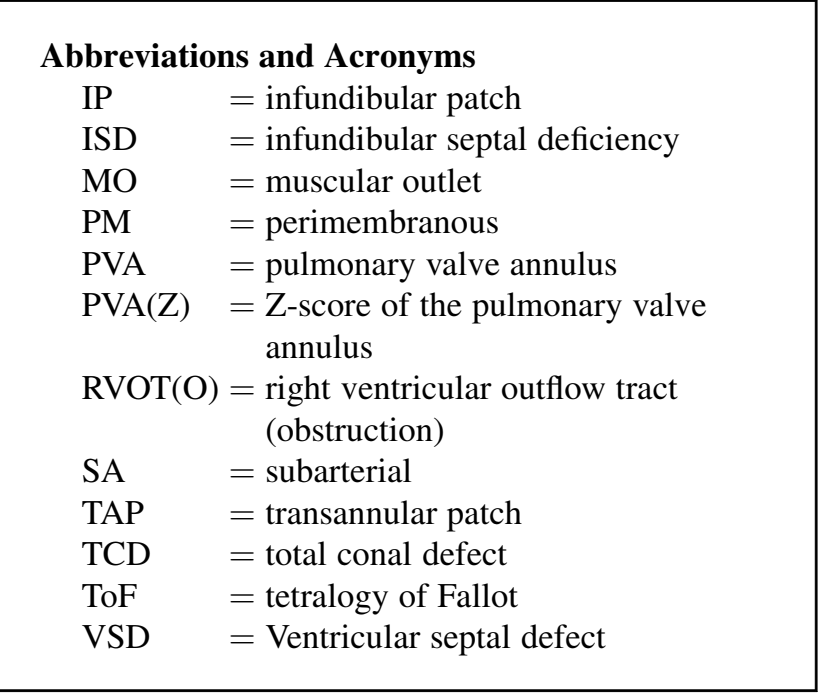

VSD patch to the pulmonary valve annulus and, consequently, restriction of PVA growth. In this study, we sought to determine the impact of ISD on the development of RVOTO in patients who were operated on under an aggressive PVA preservation strategy.

\section{MATERIALS AND METHODS}

The medical records of 90 patients who underwent total correction of ToF between June 1997 and August 2008 were reviewed retrospectively. Patients with pulmonary atresia, absent pulmonary valve syndrome, or atrioventriucular septal defect were excluded from patient enrollment. Median age at repair was 9.5 months (11 days to 57 years), and $55(61 \%)$ were males. Median body weight at operation was $8.8 \mathrm{~kg}(3.6-73.4 \mathrm{~kg})$. Of the patients $15(17 \%)$ had undergone previous systemic-to-pulmonary artery shunts. The infundibular septum was present in $75(83 \%)$ and absent (ie, ISD) in 15 patients $(17 \%)$. In patients with the infundibular septum, 54 had perimembranous (PM) VSD and 21 had muscular outlet (MO) VSD. In patients with ISD, 12 had SA VSD and 3 had total conal defect VSD. Patient characteristics according to the types of VSD are summarized in Table 1. On preoperative transthoracic echocardiography, PVA diameter was measured between the hinge points of the pulmonary valve excursion, and median z-score of PVA diameter was -2.35 (-10.5 to 4.78). To measure the size of the branch pulmonary arteries,${ }^{15}$ cardiac catheterization and angiography was performed in 81 patients $(90 \%)$, and cardiac computed tomography was performed in the remaining patients. Median pulmonary artery index (PAI) was $322 \mathrm{~mm}^{2} / \mathrm{m}^{2}\left(83\right.$ to $\left.743 \mathrm{~mm}^{2} / \mathrm{m}^{2}\right)$. For the assessment of postoperative regression of RVOT pressure gradient and growth of the PVA after PVA preservation, off-line measurements from postoperative echocardiographic studies were carried out by a single observer. For the retrospective review and collation of the data, approval by the institutional review board was obtained (2008-0277).

\section{Surgical Techniques}

Under moderate hypothermic cardiopulmonary bypass, branch pulmonary arteries were dissected and the ductus, if present, was divided. The aorta was cross-clamped, and oblique right atriotomy was made to explore the VSD and RVOT through the tricuspid valve. Parietal extension of the conal septum was extensively excised, and Hegar dilators were introduced from the right ventricle into the pulmonary valve annulus to measure the actual size of the pulmonary valve orifice. If the effective orifice diameter
TABLE 1. Patient profile according to types of ventricular septal defect

\begin{tabular}{lccr}
\hline & PM/MO & SA/TCD & $P$ value \\
\hline Number of patients & $75 / 90(83 \%)$ & $15 / 90(17 \%)$ & \\
Age at operation (median) & 9.5 & $10.5 \mathrm{~m}$ & .330 \\
Previous palliation & $13 / 75(17 \%)$ & $2 / 15(13 \%)$ & 1.000 \\
Preop. PVA(Z) (median) & -2.43 & -2.0 & .888 \\
Preoperative PAI (median) & 297 & 456 & .010 \\
Branch PA stenosis & $19 / 75(25 \%)$ & $3 / 15(20 \%)$ & 1.000 \\
Preop. AR ( $\geq$ II) & $0 / 75(0 \%)$ & $0 / 15(0 \%)$ & \\
PVA preservation & $58 / 75(78 \%)$ & $13 / 15(86 \%)$ & .729 \\
RVOT velocity (imm. postop.) & $2.5 \mathrm{~m} / \mathrm{sec}$ & $3 \mathrm{~m} / \mathrm{sec}$ & .086
\end{tabular}

$\overline{A R}(\geq I I)$, Aortic regurgitation equal to or greater than grade II; $P A$, pulmonary artery; $P A I$, pulmonary artery index $\left(\mathrm{mm}^{2} / \mathrm{m}^{2}\right) ; P M / M O$, perimembranous or muscular outlet $V S D$; Preop., preoperative; $P V A(Z), \mathrm{Z}$-value of pulmonary valve annulus diameter; RVOT (imm.postop.), right ventricular outflow tract flow velocity on immediate postoperative echocardiography; $S A / T C D$, subarterial or total conal defect VSD; VSD, ventral septal defect.

of the pulmonary valve was smaller than the equivalent of -2 of PVA(Z), which was the case in almost all patients, a longitudinal pulmonary arteriotomy was made to augment the effective valve area by employing various techniques, such as commissurotomy, division of leaflet (bicuspidalization or tricuspidalization), and excision of immobile leaflets. Hegar dilators were introduced from the pulmonary arteriotomy into the PVA again and, if PVA (Z) was still smaller than -2, the pulmonary arteriotomy was extended down to RVOT, crossing the annulus for minimal right ventriculotomy (less than $10 \mathrm{~mm}$ ) to place a small transannular patch (TAP). If PVA (Z) was greater than -2, we elected to preserve the PVA. Pulmonary arteriotomy was closed primarily or widened using a prosthetic patch (Gore Acuseal Cardiovascular Patch; Gore Medical Products, Flagstaff, Ariz) in case of supravalvar stenosis. Placement of an infundibular patch (IP) was determined either by direct measurement of RVOT using Hegar dilators or by pressure data off bypass (ie, pressure ratio of the right ventricle over the left ventricle $>0.8$ ). Acuseal patch was also used for an IP. VSD was closed by using a transatrial-transpulmonary approach in the majority of cases, with interrupted pledget-supported 6-0 polypropylene sutures and a polyethylene terephthalate fiber patch (Dacron; Bard, Atlanta, Ga). The transition of RVOT strategy from pulmonary annulus preservation to placing a transannular patch was determined on the basis of the same pressure criteria off bypass as IP placement. The surgical procedure for the RVOT reconstruction is summarized in Table 2.

In patients with the SA or TCD type of VSD, the VSD was repaired by performing a longitudinal right ventriculotomy, and an infundibular patch was placed to close the right ventriculotomy. After running into RVOTO

TABLE 2. Surgical techniques for reconstruction of right ventricular outflow tract

\begin{tabular}{lccc}
\hline RVOT reconstruction & PM/MO & SA/TCD & Total \\
\hline AP & 58 & 13 & 71 \\
No patch & 4 & 0 & 4 \\
MPA patch & 7 & 0 & 7 \\
MPA patch + IP & 47 & 13 & 60 \\
TAP & 16 & 2 & 18 \\
RV-PA conduit & 1 & 0 & 1 \\
Total & 75 & 15 & 90 \\
\hline
\end{tabular}

$A P$, Annulus preservation; $I P$, infundibular patch; $M O$, muscular outlet; $M P A$, main pulmonary artery; $P A$, right ventricle to pulmonary artery; $R V O T$, right ventricular outflow tract; $R V$ - $P M$, right ventricular perimembranous; $S A$, subarterial; $T A P$, transannular patch; $T C D$, total conal defect. 

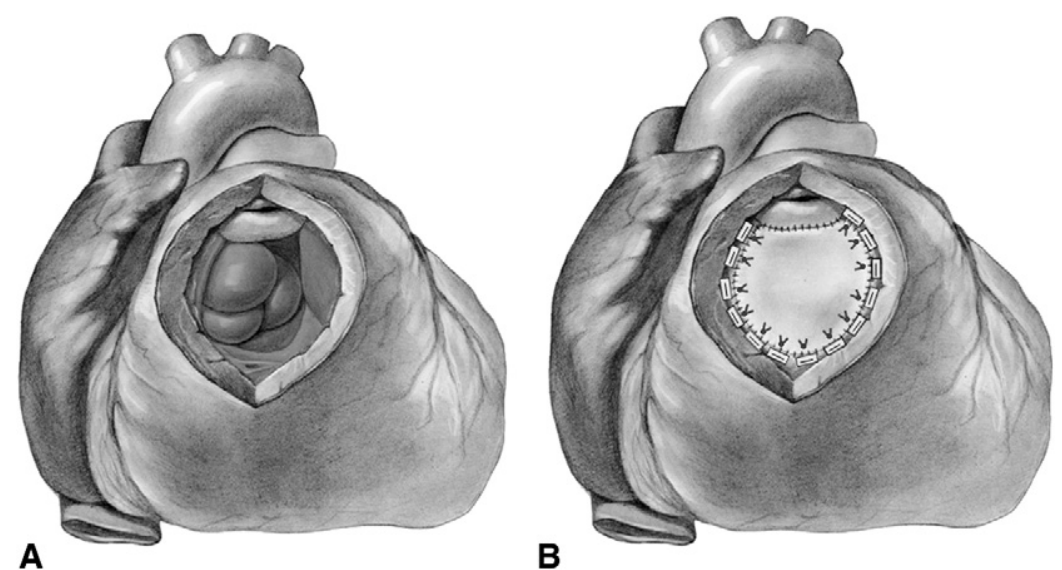

FIGURE 1. Tetralogy of Fallot with infundibular septal deficiency. A, Pulmonary valve annulus (PVA) is abutting the aortic valve annulus (AVA), which overrides the ventricular septal defect (VSD). B, The VSD is repaired using interrupted pledget-supported sutures, except for the upper margin where the VSD patch is sutured precisely on the fibrous raphae between the two semilunar valves, employing continuous suture technique using a fine monofilament suture. Anchoring of the VSD patch to the AVA or PVA may cause postoperative aortic regurgitation or right ventricular outflow tract obstruction.

after annulus preservation in patients with ISD in our early series, we modified our surgical techniques in closing the SA or TCD VSD as follows: (1) tailoring the VSD patch precisely to the actual size of the VSD so as to prevent RVOTO caused when an oversized patch bulges into an RVOT or to prevent tethering of the PVA by an undersized patch; (2) using a fine monofilament suture with a continuous running-suture technique instead of placing interrupted pledget-supported sutures in closing the upper margin of the VSD; (3) suturing exactly on the fibrous raphe between the two semilunar valves rather than on the pulmonary or aortic annulus; and (4) using patch closure instead of primary closure of the ventriculotomy (ie, placement of an infundibular patch) (Figure 1).

\section{Statistical Analysis}

Data are presented as frequencies, medians with ranges, or means with standard deviations. Logistic regression analysis was used to identify risk factors for using a TAP in the whole study group $(\mathrm{n}=90)$. Variables included in the analysis were age at operation, body weight, previous palliation, VSD types (ie, ISD), PVA Z-score, and pulmonary artery index. To assess the risk factors for RVOTO in patients with PVA preservation $(\mathrm{n}=71)$, the Cox proportional hazards model was fitted for time to reoperation for RVOTO, adjusting preoperative and intraoperative variables. Variables included in the analysis were age at operation, body weight, previous palliation, VSD type (or ISD), PVA Z-score, pulmonary artery index, cardiopulmonary bypass time, aortic cross-clamping time, and the use of an infundibular patch. Freedom from reoperation for RVOTO was represented using the Kaplan-Meier method, and stratified survival curves were plotted to explore unadjusted group difference between patients with and without the infundibular septum. To assess the impact of ISD on the postoperative changes in PVA Z-score and RVOT velocity on echocardiography, a mixed linear model (random coefficient model) was fitted for variables of interest. Analyses were conducted using SPSS version 12.0 (Korean version). A $P$ value less than .05 was considered statistically significant.

\section{RESULTS}

PVA was preserved in 71 patients $(71 / 90,79 \%)$, including 13 patients with ISD $(13 / 15,87 \%)$. The median follow-up duration was 39 months ( 2 months through 13 years). There was no early mortality and one late noncardiac death. By logistic regression analysis, PVA (Z) was identified as the only risk factor for TAP $(\mathrm{RR}=0.627,0.443-0.888, P=.009)$ (Figure 2), and ISD did not increase the risk for TAP $(P=.620)$. Among the patients with pulmonary annulus preservation $(\mathrm{n}=71), 4$ patients ( 3 with ISD) developed RVOTO, which necessitated reoperation during the follow-up period (Table 3). Cox proportional hazards model identified ISD as the only risk factor for decreased time to reoperation for RVOTO (RR: 21.9, 2.17-220, $P=.007$ ). Freedom from reoperation for RVOTO was $67 \%$ at 24 months in patients with ISD and $97 \%$ in patients with infundibular septum (Figure 3). On postoperative echocardiography, RVOT velocity $(\mathrm{m} / \mathrm{sec})$ gradually decreased during follow-up. Postoperative decrease in RVOT velocity was significant in patients with infundibular septum $(-0.011 \pm$ $0.003 /$ month, $P<.001)$ but was nonsignificant in patients

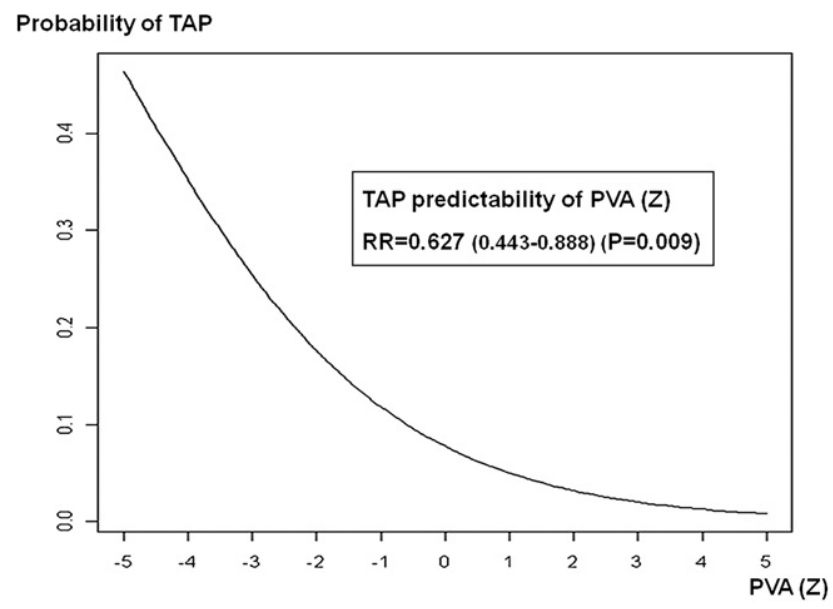

FIGURE 2. Probability of TAP according to PVA(Z). Small PVA(Z) was the only risk factor for TAP by logistic regression analysis $(R R=0.627$, $P=.007) . P V A(Z), \mathrm{Z}$-score of the pulmonary valve annulus; $T A P$, transannular patch. 
TABLE 3. Profile of patients undergoing reoperation for right ventricular outflow tract obstruction

\begin{tabular}{lccccccc}
\hline Op. age & VSD type & PVA $(Z)$ & RVOT-op. & RVOT-1 & Interval (months) & RVOT-2 & Reoperation \\
\hline 46 years & SA & -0.5 & AP & $2.7 \mathrm{~m} / \mathrm{sec}$ & $7 \mathrm{~m}$ & $3.5 \mathrm{~m} / \mathrm{sec}$ & PVR, TVR \\
8 months & MO & -3.83 & AP & $3.5 \mathrm{~m} / \mathrm{sec}$ & $25 \mathrm{~m}$ & $4 \mathrm{~m} / \mathrm{sec}$ & Pulmonary valvotomy \\
9 months & TCD & -1.04 & AP & $3.5 \mathrm{~m} / \mathrm{sec}$ & $8 \mathrm{~m}$ & $4 \mathrm{~m} / \mathrm{sec}$ & TAP \\
11 months & SA & -3.13 & AP & $3 \mathrm{~m} / \mathrm{sec}$ & $16 \mathrm{~m}$ & $5.3 \mathrm{~m} / \mathrm{sec}$ & TAP \\
\hline
\end{tabular}

$A P$, Pulmonary valve annulus preservation; Interval, interval between the initial operation and reoperation; $M O$, muscular outlet; $O p$., operation; $P A I$, pulmonary artery index $\left(\mathrm{mm}^{2} / \mathrm{m}^{2}\right) ; P V A(Z)$, Z-value of the preoperative pulmonary valve annulus diameter; $P V R$, pulmonary valve replacement; $R V O T$ op., reconstruction method; $R V O T O$, right ventricular outflow tract obstruction; $R V O T$-1, RVOT velocity on immediate postoperative echocardiography; $R V O T-2$, RVOT velocity on echocardiography prior to reoperation; $S A$, Subarterial; TAP, transannular patch; TCD, total conal defect; TVR, tricuspid valve replacement; VSD, ventricular septal defect.

with ISD $(-0.0004 \pm 0.007 /$ month, $P=.954)$. There was no intergroup difference $(P=.145)$ (Figure 4). Among the patients who underwent repair with PVA preservation during infancy $(n=43)$, postoperative increase in PVA $(Z)$ was significant in patients with infundibular septum (+0.021/month, $P=.009)$, but nonsignificant in patients with ISD (-0.021/month, $P=.306)$, with a marginal intergroup difference $(P=.056)$ (Figure 5). When analyzing 25 postoperative echocardiographic data from the patients with ISD who had repair with annulus preservation during infancy $(\mathrm{n}=8)$, a strong correlation was found between postoperative $\mathrm{PVA}(\mathrm{Z})$ and RVOT velocity $\left(\mathrm{r}^{2}=0.537\right)$.

\section{DISCUSSION}

Differing from perimembranous or muscular VSD, SA VSD has extremely uneven geographic distribution. It is more prevalent in northeast Asia than in the Occident. This is also the case for the types of VSD in ToF. In Japan, for instance, the association of SA VSD with ToF has been reported to be as high as $20 \% .^{16,17}$ Thus, studies of SA VSD in ToF have been conducted much more frequently in Asia, especially in Japan. $7,9,16,17$ Previous studies implied a higher rate of $\mathrm{TAP}^{7,8,17-19}$ a higher risk for postoperative RVOTO, ${ }^{7,16}$ common development of postoperative aortic

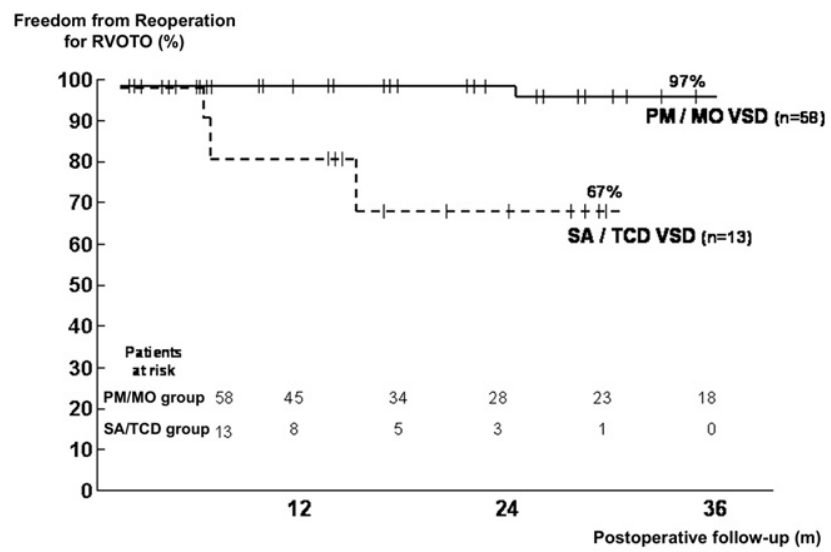

FIGURE 3. Freedom from reoperation for RVOTO stratified by types of ventricular septal defect. $M O$, Muscular outlet; $P M$, perimembranous outlet; RVOTO, right ventricular outflow tract obstruction; $S A$, subarterial; $T C D$, total conal defect; $V S D$, ventricular septal defect. regurgitation, ${ }^{7}$ and even higher mortality ${ }^{9,18}$ in this subset. However, these studies have several pitfalls. With respect to the frequent need for TAP, we speculate that deficient infundibular septum is not necessarily a risk factor for TAP because TAP probability could well be determined by PVA size alone, and because patients with SA VSD may have even larger PVAs ${ }^{18}$ than patients with other types of VSD. Thus, the higher incidence of TAP in the previous studies might have had more to do with institutional bias or individual surgeons' preferences. Additionally, the age at repair in the previous reports is older than that of the contemporary series, which are composed primarily of patients who undergo repair during infancy. Furthermore, the risk for RVOTO after ToF repair cannot be assessed plausibly without taking the RVOT reconstruction strategy into account; that is, the risk for RVOTO can be analyzed plausibly in patients who are operated on by surgeons who favor aggressive PVA preservation because over-reliance on TAP may alleviate the deleterious effect of ISD on the development of postoperative RVOTO.

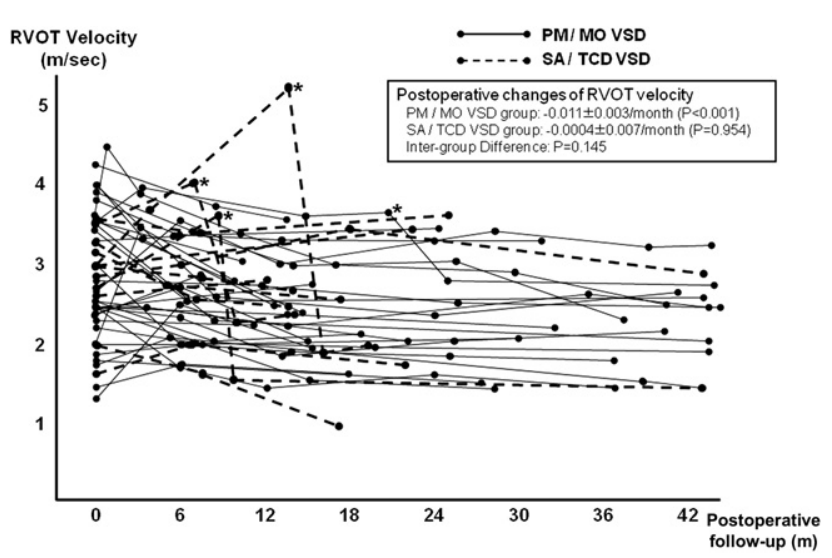

FIGURE 4. Postoperative changes of RVOT velocity in patients with pulmonary valve annulus preservation $(\mathrm{n}=71)$. During the follow-up, RVOT velocity decrement was significant in patients with PM/MO VSD $(P<.001)$ and nonsignificant in patients with SA/TCD VSD $(P=.954)$. The intergroup difference was not statistically significant $(P=.145) . M O$, Muscular outlet; $P M$, perimembranous; $R V O T$, right ventricular outflow tract; $S A$, subarterial; $T C D$, total conal defect; $V S D$, ventricular septal defect. *Reoperation for RVOTO. **Data from the patients whose echocardiographic follow-up times were shorter than 12 months were omitted from the illustration for clarification. 


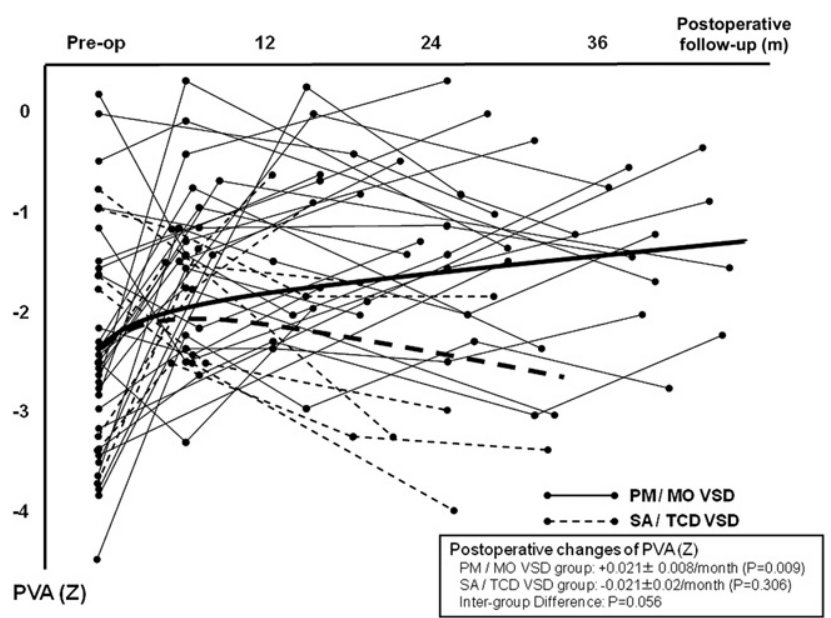

FIGURE 5. Postoperative changes of $\mathrm{PVA}(\mathrm{Z})$ in patients with pulmonary valve annulus preservation, whose age at repair was less than 12 months $(\mathrm{n}=43)$. During the follow-up, $\operatorname{PVA}(\mathrm{Z})$ increment was significant in patients with $\mathrm{PM} / \mathrm{MO} \operatorname{VSD}(P=.009)$ and nonsignificant in patients with SA/TCD VSD $(P=.306)$, with a marginal intergroup difference $(P=.056) . M O$, Muscular outlet; $P M$, perimembranous; $P V A(Z)$, Z-value of pulmonary valve annulus diameter; $S A$, subarterial; $T C D$, total conal defect; $V S D$, ventricular septal defect. *Data from the patients whose echocardiographic follow-up was shorter than 12 months were omitted from the illustration for clarification.

Our study is distinctive compared to the previous reports in that postoperative outcome of ToF with SA VSD was looked at primarily in patients who had had repair during infancy (ie, median age at repair was 9 months) under aggressive PVA preservation strategy (ie, an $80 \%$ rate of annulus preservation). From our recent experience, we have inferred that higher risk for RVOTO in patients with ISD may be related to the surgical technique used for VSD closure as well as to unique anatomic predisposition to RVOTO.

Three possible explanations can be given for frequent postoperative RVOTO in the patients with ISD: (1) subpulmonary extension of the VSD and anchoring of a VSD patch to the pulmonary annulus may restrict the growth of the PVA, as was demonstrated in isolated $\mathrm{SA} \mathrm{VSD}^{20}$; (2) the posterior wall of the infundibulum formed by prosthetic material (ie, a VSD patch) may restrict the growth of the infundibulum; and (3) an oversized VSD patch protruding into the RVOT may cause flow turbulence and fibrotic tissue growth more easily in this group than in others. Demonstration of a lack of regression in RVOTO and no outgrowth of PVA over somatic growth in infants with SA or TCD VSD substantiate the former two hypotheses, whereas the development of RVOTO in a 48-year-old patient with SA VSD in our early series may be attributed to the last hypothesis.

In this study, all patients who had an ISD had right ventriculotomy, including 13 who received an IP and 2 who received a TAP. It has been disputed whether the use of an IP in ToF may lead to aneurismal dilation of the RVOT, ${ }^{2}$ which has the same deleterious effect as a TAP on long-term outcome. Nevertheless, we believe that right ventriculotomy and the use of an IP are essential procedures in pulmonary annulus preservation in patients with ISD: (1) suturing the upper margin of a VSD can be performed precisely through a right ventriculotomy; and (2) augmentation of the RVOT using an IP is strongly recommended, given that the posterior wall of the infundibulum is not formed by native tissue but is reconstructed using a prosthetic patch (ie, a VSD patch). ${ }^{18}$

\section{Limitation of the Study}

Even if we were able to demonstrate that ISD in ToF is a risk factor for postoperative RVOTO, no preoperative risk factor for RVOTO was identified within the subgroup of patients with ISD. Preoperative PVA(Z) in 3 patients with ISD who developed RVOTO after pulmonary annulus preservation was $-0.5,-1.04$, and -3.13 , respectively, which was not significantly smaller than that which occurred in the rest of the patients with ISD. We also found that growth of the PVA was restricted in the patients with ISD, but it is uncertain whether restriction of PVA growth is related to an anatomic predisposition or has more to do with the surgical technique employed in our early series (ie, a VSD patch anchored to the PVA using thick interrupted pledgetted sutures). Thus, this study may not help us to isolate patients with ISD who should undergo transannular patching in the first place. However, if the risk for postoperative RVOTO can be alleviated, at least in part, by appropriate modifications in surgical technique, we may still have a little more room for pursuing PVA preservation in this subset, especially in patients with marginally small PVAs.

\section{CONCLUSIONS}

In the surgical correction of ToF, the size of the PVA was the only risk factor for the placement of TAP, and ISD did not preclude pulmonary annulus preservation. However, once the PVA was preserved, patients with ISD showed restricted growth of the PVA and higher risk for RVOTO, which may be attributed to inappropriate surgical techniques and to an anatomic predisposition to postoperative RVOTO. In ToF with ISD, special care should be taken upon initial repair employing PVA preservation strategy. Because there seems to be a tendency to increased late RVOTO when the PVA is spared in ToF with an absent ISD, the threshold for placing a transannular patch should be lowered, using more strict criteria for intraoperative physiologic study as well as preoperative PVA size. Further study to identify risk factors for RVOTO after annulus preservation within the subgroup is mandatory.

\section{References}

1. Lillehei CW, Cohen M, Warden HE, Read RC, Aust JB, Dewall RA, Varco RL. Direct vision intracardiac surgical correction of the tetralogy of Fallot, pentalogy of Fallot, and pulmonary atresia defects: report of first ten cases. Ann Surg. 1955 142:418-42. 
2. d'Udekem Y, Ovaert C, Grandjean F, Gerin V, Cailteux M, Shango-Lody P, et al. Tetralogy of Fallot: transannular and right ventricular patching equally affect late functional status. Circulation. 2000;102(Suppl 3):116-52.

3. Davlouros PA, Kilner PJ, Hornung TS, Li W, Francis JM, Moon JCC, Smith GC, et al. Right ventricular function in adults with repaired tetralogy of Fallot assessed with cardiovascular magnetic resonance imaging: detrimental role of right ventricular outflow aneurysms or akinesia and adverse right-to-left ventricular interaction. J Am Coll Cardiol. 2002;40:2044-52.

4. Sachdev MS, Bhagyavathy A, Varghese R, Coelho R, Kumar RS. Right ventricular diastolic function after repair of tetralogy of Fallot. Pediatr Cardiol. 2006;27:250-5.

5. Zahka KG, Horneffer PJ, Rowe SA, Neill CA, Manolio TA, Kidd L, Gardner TJ. Long-term valvular fraction after total repair of tetralogy of Fallot: relation to ventricular arrhythmias. Circulation. 1988;78(Suppl III):14-9.

6. Gatzoulis MA, Balaji S, Webber SA, Siu SC, Hokanson JS, Poile C, et al. Risk factors for arrhythmia and sudden cardiac death late after repair of tetralogy of Fallot: a multicentre study. Lancet. 2000;356:975-81.

7. Ando M, Takahashi Y, Kikuchi T, Tatsuno K. Tetralogy of Fallot with subarterial ventricular septal defect. Ann Thorac Surg. 2003;76:1059-64.

8. de Leval MR, Pozzi M, Starnes V, Sullivan ID, Stark J, Somerville J, et al. Surgical management of doubly committed subarterial ventricular septal defect. Circulation. 1988;78(Suppl III):40-6.

9. Okita Y, Miki S, Ueda Y, Tahata T, Sakai T, Matsuyama K, et al. Early and late results of repair of tetralogy of Fallot with subarterial ventricular septal defect: a comparative evaluation of tetralogy with perimembranous ventricular septal defect. J Thorac Cardiovasc Surg. 1995;110:180-5.

10. Yasui H, Nakamura Y, Kado H, Yonenaga K, Aso T, Sunagawa H, et al. Preservation of the pulmonary valve during intracardiac repair of tetralogy of Fallot. $J$ Cardiovasc Surg. 1992;33:545-53.
11. Stewart RD, Backer CL, Young L, Mavroudis C. Tetralogy of Fallot: results of a pulmonary valve-sparing strategy. Ann Thorac Surg. 2005;80: 1431-8.

12. Rao V, Kadletz M, Hornberger LK, Freedom RM, Black MD. Preservation of the pulmonary valve complex in tetralogy of Fallot: how small is too small? Ann Thorac Surg. 2000;69:176-9.

13. Van Arsdell G, Yun TJ. An apology for primary repair of tetralogy of Fallot. Semin Thorac Cardiovasc Surg Pediatr Card Surg Annu. 2005;128-31.

14. Antunes MJ, Castela E, Sanches MF, Melo AS. Preservation of the pulmonary annulus in total correction of tetralogy of Fallot. Eur J Cardiothorac Surg. 1991;5:528-33

15. Nakada S, Imai Y, Takanashi Y, Kurosawa H, Tezuka K, Nakazawa M, et al. A new method for the quantitative standardization of cross-sectional areas of the pulmonary arteries in congenital heart disease with decreased pulmonary blood flow. J Thorac Cardiovasc Surg. 1984;88:610-9.

16. Matsuda H, Ihara K, Mori T, Kitamura S, Kawashima Y. Tetralogy of Fallot associated with aortic insufficiency. Ann Thorac Surg. 1980;29:529-33.

17. Kurosawa H, Yanagisawa M, Kainuma Y. Tetralogy of Fallot with total conal defect. Jpn J Thorac Surg. 1976;29:229-36.

18. Vargas FJ, Kreutzer GO, Pedrini M, Capelli H. Rodriguez Coronel A. Tetralogy of Fallot with subarterial ventricular septal defect: diagnostic and surgical considerations. J Thorac Cardiovasc Surg. 1986;92:908-12.

19. Neirotti R, Galindez E, Kreutzer G, Coronel AR, Pedrini M, Becu L. Tetralogy of Fallot with subpulmonary ventricular septal defect. Ann Thorac Surg. 1978;25: 51-6.

20. Chang YH, Sung SC, Lee HD, Ban JE, Choo KS, Lee YS. Does patch closure of subarterial ventricular septal defect affect the growth of pulmonary valve? Eur J Cardiothorac Surg. 2007;32:149-55. 